\title{
Development and Evaluation of Diclofenac sodium Controlled Release Dosage Forms Using Natural, Hydrophilic and Hydrophobic Polymers and its Comparative Studies
}

\author{
Divvela Hema Naga Durga*, Duppala Lohithasu, Kolapalli Venkata Ramana Murthy \\ Division of Pharmaceutical Technology, A.U. College of Pharmaceutical Sciences, Andhra University, Visakhapatnam-530003, \\ Andhra Pradesh, INDIA.
}

\begin{abstract}
The aim of the present study is to develop the controlled release dosage form of diclofenac using hydrophilic polymers (xanthan gum from natural origin, hydroxy propyl methyl cellulose $\mathrm{K} 100 \mathrm{M}$ from semisynthetic origin) and hydrophobic polymer (compritol 888 ATO from synthetic origin). Diclofenac sodium matrix tablets were prepared by xanthan gum and hydroxy propyl methyl cellulose by wet granulation method. Hot melt granulation method was used for compritol as it was insoluble polymer. Fourier transform infrared spectroscopy (FTIR) analysis, differential scanning calorimetry (DSC) and $\mathrm{X}$-Ray diffraction (XRD) studies indicated that there was no interaction between drug and polymers. Matrix tablets were formulated according to formulae and evaluated the suitability for controlled release systems for $24 \mathrm{~h}$. Tablets prepared with xanthan gum, hydroxy propyl methyl cellulose and compritol matrix tablets showed zero order drug release. The hardness for all the formulations found to be in the range of $4-5 \mathrm{~kg} / \mathrm{cm}^{2}$. The friability values of all formulations were found to be less than $1 \%$. The drug content of each individual preparation was found to be within the specified limits of the stated amount of diclofenac sodium. XGD4, HPD4 and CD2 formulations were considered as optimum formulations for oral controlled release of diclofenac sodium.
\end{abstract}

Key words: Diclofenac sodium, Hydroxy propyl methyl cellulose K 100M, Xanthan gum, controlled release dosage forms, Compritol 888 ATO.

\section{INTRODUCTION}

Oral administration is the frequently used route of drug administration and is the most convenient and economic. It is frequently used route because gastrointestinal (GI) physiology offers more flexibility in dosage from design than other routes. ${ }^{1-4}$ Among different oral dosage forms tablets are popular due to ease of preparation, economy and accuracy of dose. However, immediate release tablets suffer disadvantages like frequent dosing for short biological half life drugs, fluctuations in plasma concentration. To minimize these disadvantages controlled release tablets were designed. These deliver the drug locally in the gastrointestinal tract
(GIT) or systemically at predetermined rate for specific period of time by different types of mechanism. ${ }^{5-8}$

Diclofenac sodium is a no steroidal antiinflammatory drug (NSAID) that exhibits anti-inflammatory, analgesic and antipyretic activities.It is a heterocyclic aryl acetic acid derivative and non-selective COX inhibitor. Diclofenac sodium is a white to slightly yellowish crystalline powder, odourless, hygroscopic powder. It is freely soluble in methanol, soluble in ethanol, sparingly soluble in water and glacial acetic acid, practically insoluble in chloroform, ether and toluene. The $\mathrm{pK}_{\mathrm{a}}$ of diclofenac sodium is
Submission Date: 19-08-2016; Revision Date: 17-11-2016; Accepted Date: 17-11-2016

DOI: 10.5530/ijper.51.1.16 Correspondence: Divvela Hema Naga Durga, Division of Pharmaceutical Technology, A.U. College of Pharmaceutical Sciences, Andhra University, Visakhapatnam-530003, Andhra Pradesh, India. Ph no: 919491894432 E-mail: hemanagadurgad@ gmail.com

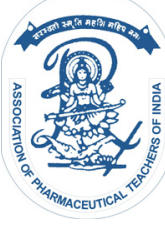

www.ijper.org 
3.80 at $25^{\circ} \mathrm{C}$. The experimental $\log \mathrm{P}$ (n-octanol/water) and $\mathrm{C} \log \mathrm{P}$ values of diclofenac sodium are 4.40 and 4.71 respectively. Its melting point is $280^{\circ} \mathrm{C}$ with decomposition. ${ }^{9}$

Xanthan gum occurs as a cream or white-coloured, odourless, free-flowing, fine powder. It is widely used in oral and topical pharmaceutical formulations, cosmetics and foods as a suspending and stabilizing agent. It is used as a thickening and emulsifying agent. It is used to prepare controlled release matrix tablets. It is used in ophthalmic liquid dosage forms and used to increase the bioadhesive strength in vaginal formulations. ${ }^{10-18}$

Hydroxy propyl methyl cellulose is an odourless, tasteless, white or creamy-white fibrous or granular powder. It is used as tablet binder, film-former in tablet film coating and extended release matrix tablet formulations. Lower viscosity grades are used in aqueous film coating and higher viscosity grades are used in solvent film coating. The concentration varies from 2 to $10 \% \mathrm{w} / \mathrm{v}$ depends on the viscosity grade of the polymer. 2 to $5 \% \mathrm{w} / \mathrm{v}$ used as tablet binder and high viscosity grades are used to retard the drug from matrix in tablets and capsules. In eye drops and artificial tear solutions used as thickening agent at 0.45 to $1 \% \mathrm{w} / \mathrm{v}$ concentration. It is used in protective colloids, which prevents droplets and particles from coalescing. It is used as emulsifier, suspending agent and stabilizer in gels and adhesive in plastic bandages. Here after hydroxy propyl methyl cellulose K 100M was written as hydroxy propyl methyl cellulose (HPMC) ${ }^{19-24}$ Compritol 888 ATO occurs as a fine white to off white free flowing powder or hard waxy mass with a faint odour, tasteless, non reactive with other formulation ingredients. It is used in cosmetics, foods and oral pharmaceutical formulations. It is used in the preparation of controlled release tablets as a matrix forming agent of water soluble drugs by melt granulation method $(>10 \% \mathrm{w} / \mathrm{w})$, as a lubricant in oral solid dosage formulations ( 1 to $3 \% \mathrm{w} / \mathrm{w}$ ), as a hot melt coating agent sprayed on to a powder and for the formation of solid lipid nanoparticles. In cosmetics it is mainly used as a viscosity-increasing agent ( 1 to $15 \% \mathrm{w} / \mathrm{v}){ }^{25-32}$

\section{MATERIALS AND METHODS}

\section{Materials}

Diclofenac sodium is obtained as a gift sample from Crips Laboratory Pvt. Ltd, Visakhapatnam. Xanthan gum and hydroxy propyl methyl cellulose obtained from A.R Loba chemical Pvt. Ltd, Mumbai. Compritol 888 ATO wasprovided by Colorcon Asia Pvt. Ltd, Mumbai. All other chemicals used were of analytical grade.

\section{Preparation of matrix tablets of diclofenac sodium}

Diclofenac sodium matrix tablets were prepared by mixing the ingredients previously passed through sieve No. 100 sufficient for a batch of 200 tablets weighed according to the formulas shown in Table 1 to 3 . The drug was geometrically mixed with polymer (xanthan gum/hydroxy propyl methyl cellulose) until a homogenous blend was achieved. $2 \% \mathrm{w} / \mathrm{v}$ xanthan gum dispersion in water was used as granulating agent for preparation of xanthan gum matrix tablets respectively. $5 \% \mathrm{w} / \mathrm{v}$ poly vinyl pyrrolidone (PVP) in ethanol was used as granulating agent for the preparation of hydroxy propyl methyl cellulose matrix tablets. Granules were prepared by passing mass initially through sieve No. 12 (nominal mesh aperture size $1.4 \mathrm{~mm}$ and approximate $\%$ sieving area 44) and dried at $50{ }^{\circ} \mathrm{C}$ in hot air oven. Dried granules passed through sieve No. 22 (nominal mesh aperture size $710 \mu \mathrm{m}$ and approximate \% sieving area 37). Granules of compritol were made by hot melt granulation method. Compritol was melted in a porcelain dish on a water bath at $75{ }^{\circ} \mathrm{C}$ for $3 \mathrm{~min}$. Diclofenac sodium was added gradually with stirring until uniformly mixed. The molten mixture was allowed to cool slowly while stirring and solidify at room temperature. The solidified mass was crushed in mortar and passed through a sieve No. 22. Then granules were lubricated with magnesium stearate and talc and blended for 3 min in polybag. All granules made with different polymers showed good flow characters. Hence, the final blend was compressed into tablets on a 16-station rotary punching machine (M/s. Cadmach Machinery Co. Pvt. Ltd., India) using $8 \mathrm{~mm}$ or $10 \mathrm{~mm}$ round flat punches with compression force sufficient to obtain hardness of 4 to $5 \mathrm{~kg} / \mathrm{cm}^{2}$.

\section{Evaluation of prepared matrix tablets ${ }^{33-44}$ Uniformity of weight}

According to Indian Pharmacopoeia, twenty tablets were selected at random and average weight was determined. Tablets were weighted individually and the percentage deviation of its weight from the average weight was determined. Prepared tablets complies the test if not more than two of the individual weights deviated from the average weight by more than the 7.5 percentage and none deviate more than twice the percentage 7.5 for tablets weighing in the range of $>80-<250 \mathrm{mg}$.

\section{Hardness}

Five tablets were selected at random and the hardness of each tablet was measured using Monsanto hardness tester. 


\begin{tabular}{|c|c|c|c|c|c|c|}
\hline \multirow{2}{*}{$\begin{array}{l}\text { Ingredients } \\
\text { (mg per tablet) }\end{array}$} & \multicolumn{6}{|c|}{ Formula code } \\
\hline & XGD1 & XGD2 & XGD3 & XGD4 & XGD5 & XGD6 \\
\hline Diclofenac sodium & 100 & 100 & 100 & 100 & 100 & 100 \\
\hline Xanthan gum & 20 & 40 & 60 & 80 & 100 & 120 \\
\hline $2 \% \mathrm{w} / \mathrm{v}$ dispersion of xanthan gum equivalent to & 2 & 2 & 2 & 2 & 2 & 2 \\
\hline Magnesium stearate & 3 & 3 & 3 & 3 & 3 & 3 \\
\hline Talc & 2 & 2 & 2 & 2 & 2 & 2 \\
\hline Tablet weight (mg) & 127 & 147 & 167 & 187 & 207 & 227 \\
\hline
\end{tabular}

Table 2: Formulas of hydroxy propyl methyl cellulose matrix tablets of diclofenac sodium (hpd1 to hpd6)

\begin{tabular}{|c|c|c|c|c|c|c|}
\hline \multirow{2}{*}{$\begin{array}{c}\text { Ingredients } \\
\text { (mg per tablet) }\end{array}$} & \multicolumn{7}{|c|}{ Formula code } \\
\cline { 2 - 7 } & HPD1 & HPD2 & HPD3 & HPD4 & HPD5 & HPD6 \\
\hline Diclofenac sodium & 100 & 100 & 100 & 100 & 100 & 100 \\
\hline HPMC K 100M & 10 & 20 & 30 & 40 & 50 & 60 \\
\hline Poly vinyl pyrrolidone (PVP) 5\% w/v & 5 & 5 & 5 & 5 & 5 & 5 \\
\hline Magnesium stearate & 3 & 3 & 3 & 3 & 3 & 3 \\
\hline Talc & 2 & 2 & 2 & 2 & 2 & 2 \\
\hline Tablet weight (mg) & 120 & 130 & 140 & 150 & 160 & 170 \\
\hline
\end{tabular}

\begin{tabular}{|c|c|c|c|c|}
\hline \begin{tabular}{c} 
Table 3: Formulas of compritol matrix tablets of diclofenac sodium (CD1 to CD4) \\
\hline $\begin{array}{c}\text { Ingredients } \\
\text { (mg per tablet) }\end{array}$
\end{tabular} & \multicolumn{4}{|c|}{ Formula code } \\
\cline { 2 - 5 } & CD1 & CD2 & CD3 & CD4 \\
\hline Diclofenac sodium & 100 & 100 & 100 & 100 \\
\hline Compritol 888 ATO & 10 & 20 & 30 & 40 \\
\hline Magnesium stearate & 3 & 3 & 3 & 3 \\
\hline Talc & 2 & 2 & 2 & 2 \\
\hline Tablet weight $(\mathbf{m g})$ & 115 & 125 & 135 & 145 \\
\hline
\end{tabular}

\section{Thickness}

Five tablets were selected at random and thickness of the each tablet was evaluated by Vernier callipers. Mean and standard deviation was calculated.

\section{Friability}

This test is applicable to compressed tablets and is intended to determine the physical strength of tablets. The friability test was carried out in Roche friabilator. The tablets equivalent to a weight $6.5 \mathrm{~g}$ were selected randomly and initial weight $\left(\mathrm{w}_{0}\right)$ was noted and put in a rotating drum. Then, they were subjected to 100 falls of 6 inches height ( $25 \mathrm{rpm}$ for four minutes). After completion of rotations, the tablets were deducted and weighed them accurately (w). The test was run only once unless the results are difficult to interpret or if the weight loss was greater, in that case the test was repeated twice and the mean of the three tests was determined. The percent loss in weight should not be greater than $1.0 \%$ is acceptable. The percent loss in weight or friability ( $\mathrm{f}$ ) was calculated by equation given below.

$$
\mathrm{f}=\left(1-\frac{\mathrm{w}}{\mathrm{w}_{0}}\right) \times 100
$$

\section{Estimation of drug content}

From each batch, 10 tablets were randomly collected, powdered in a glass mortar individually and the powder equivalent to $50 \mathrm{mg}$ of diclofenac sodium was placed in a $50 \mathrm{~mL}$ volumetric flask. The drug was extracted with $25 \mathrm{~mL}$ of methanol with vigorous shaking on a mechanical shaker for $1 \mathrm{~h}$ and filtered into a $50 \mathrm{~mL}$ volumetric flask through $0.45 \mu \mathrm{m}$ Millipore nylon filter disc and the filtrate was made up to mark with methanol. Further appropriate dilutions were made with $\mathrm{pH} 6.8$ buffer and the absorbance was measured at $276 \mathrm{~nm}$ against blank prepared under same conditions without drug using UV visible spectrophotometer. 


\section{In vitro dissolution studies}

Dissolution test was carried out using USP XXIV dissolution test apparatus (M/s. Lab India, Model: DISSO 2000) employing the paddle stirrer (Apparatus II) and the stirring rate was $50 \mathrm{rpm}$. The $0.1 \mathrm{~N} \mathrm{HCl}(\mathrm{pH} 1.2)$ was for the first $2 \mathrm{~h}$ and $\mathrm{pH} 6.8$ phosphate buffer was used for remaining $24 \mathrm{~h}$ as dissolution medium $(900 \mathrm{~mL})$ and was maintained at temperature $37 \pm 0.5^{\circ} \mathrm{C}$. Samples of $5 \mathrm{~mL}$ were withdrawn at predetermined time intervals with syringe fitted with a pre filter and immediately replaced with $5 \mathrm{~mL}$ of fresh medium maintained at temperature $37 \pm 0.5{ }^{\circ} \mathrm{C}$. The collected samples were diluted suitably with dissolution medium, wherever necessary and were analyzed for the diclofenac sodium content spectrophotometric method at $276 \mathrm{~nm}$. Each dissolution study was performed for three times. The mean of percentage of diclofenac released from tablets and standard deviation were calculated.

\section{Drug release kinetics of the matrix tablets}

The analysis of drug release mechanism from a pharmaceutical dosage form is an important but complicated process. The dissolution data is fitted to popular release models such as zero order, first order, diffusion and erosion. The order of drug release from matrix systems was described by using zero order kinetics or first order kinetics. The mechanism of drug release from matrix systems was studied by using higuchi and erosion equations.

\section{Zero order release kinetics}

It defines a linear relationship between the fractions of drug released versus time.

$$
\mathrm{Q}=\mathrm{k}_{0} \mathrm{t}
$$

Where, $\mathrm{Q}$ is the fraction of drug released at time $\mathrm{t}$ and $\mathrm{k}_{\mathrm{o}}$ is the zero order release rate constant.A plot of the fraction of drug released against time will be linear if the release obeys zero order release kinetics.

\section{First order release kinetics}

Wagner assuming that the exposed surface area of a tablet decreased exponentially with time during dissolution process suggested that drug release from most slow release tablets could be described adequately by apparent first-order kinetics.

$$
\operatorname{In}(1-\mathrm{Q})=-\mathrm{k}_{1} \mathrm{t}
$$

Where, $\mathrm{Q}$ is the fraction of drug released at time $(\mathrm{t})$ and $\mathrm{k}_{1}$ is the first order release rate constant.A plot of the logarithm of the fraction of drug remained against time will be linear if the release obeys first order release kinetics.

\section{Higuchi equation}

It defines a linear dependence of the active fraction released per unit of surface $(\mathrm{Q})$ on the square root of time.

$$
\mathrm{Q}=\mathrm{k}_{2} \mathrm{t}^{1 / 2}
$$

Where, $\mathrm{Q}$ is the fraction of drug released at time $\mathrm{t}, \mathrm{k}_{2}$ is the release rate constant. A plot of the fraction of drug released against square root of time will be linear if the release obeys Higuchi equation.

\section{Erosion equation}

This equation defines the drug release based on tablet erosion alone.

$$
\mathrm{Q}=1-\left(1-\mathrm{k}_{3} \mathrm{t}\right)^{3}
$$

Where, $\mathrm{Q}$ is the fraction of drug released at time $t, \mathrm{k}_{3}$ is the release rate constant. A plot between [1-(1- $\left.\mathrm{Q}^{1 / 3}\right]$ against time will be linear if the release obeys erosion equation.

\section{RESULTS AND DISCUSSION}

Matrix tablets were formulated according to formulae and evaluated the suitability for controlled release systems for $24 \mathrm{~h}$. Diclofenac sodium matrix tablets were prepared by xanthan gum and hydroxy propyl methyl cellulose by wet granulation method. Hot melt granulation method was used for compritol as it was insoluble polymer. The angle of repose values of granules were found to be xanthan gum (24-31), hydroxy propyl methyl cellulose (22-30) and CD2 (21-28) which indicated that all the granules were free flowing and good enough for punching. The tablets were compressed using $8 \mathrm{~mm}$ or $10 \mathrm{~mm}$ punches depending on the total weight of the tablet. The weight of the tablet (XGD5 and XGD6) more than $200 \mathrm{mg}$ were punched by $10 \mathrm{~mm}$ punch and remaining were punched by $8 \mathrm{~mm}$ punch. The prepared tablets were evaluated for their tabletting characters and drug release.

\section{Uniformity of weight, hardness, thickness, friability and drug content:}

The results of uniformity of weight, hardness, thickness, friability and drugcontent for all formulations were calculated and results are given in Table 4. The weight variation of the tablets was complied with the compendia standards for uniformity of weight. The \% deviation of the all the formulations were within the range and less than the standard value $(7.5 \%)$. The hardness for all the formulations found to be in the range of $4-5 \mathrm{~kg} / \mathrm{cm}^{2}$. The friability values of all formulations were found to be less than $1 \%$. The drug content of each individual 


\begin{tabular}{|c|c|c|c|c|c|}
\hline Formulation & $\begin{array}{l}\text { Uniformity of weight }{ }^{a} \\
\text { (mg) }\end{array}$ & $\begin{array}{l}\text { Hardness }^{b} \\
\left(\mathbf{k g} / \mathrm{cm}^{2}\right)\end{array}$ & $\begin{array}{l}\text { Thickness } \\
(\mathbf{m m})^{\mathrm{b}}\end{array}$ & $\begin{array}{c}\text { Friability }^{c} \\
(\%)\end{array}$ & $\begin{array}{c}\text { Drug content } \\
(\%)\end{array}$ \\
\hline XGD1 & $127.27 \pm 0.8379$ & $4-5$ & $3.19 \pm 0.08$ & 0.58 & $99.58 \pm 1.05$ \\
\hline XGD2 & $147.34 \pm 0.9471$ & $4-5$ & $3.62 \pm 0.15$ & 0.47 & $99.57 \pm 0.84$ \\
\hline XGD3 & $168.21 \pm 1.2584$ & $4-5$ & $3.76 \pm 0.08$ & 0.49 & $100.21 \pm 0.51$ \\
\hline XGD4 & $187.34 \pm 0.9678$ & $4-5$ & $3.84 \pm 0.04$ & 0.34 & $99.64 \pm 0.76$ \\
\hline XGD5 & $207.45 \pm 1.3248$ & $4-5$ & $2.93 \pm 0.12$ & 0.37 & $99.83 \pm 0.65$ \\
\hline XGD6 & $228.14 \pm 0.7904$ & $4-5$ & $3.16 \pm 0.09$ & 0.29 & $99.71 \pm 1.23$ \\
\hline HPD1 & $120.61 \pm 0.4067$ & $4-5$ & $3.21 \pm 0.04$ & 0.43 & $99.48 \pm 0.85$ \\
\hline HPD2 & $130.43 \pm 1.1440$ & $4-5$ & $3.24 \pm 0.07$ & 0.51 & $99.78 \pm 1.36$ \\
\hline HPD3 & $140.66 \pm 0.4889$ & $4-5$ & $3.28 \pm 0.15$ & 0.37 & $100.17 \pm 2.18$ \\
\hline HPD4 & $150.17 \pm 0.8068$ & $4-5$ & $3.36 \pm 0.06$ & 0.31 & $99.54 \pm 1.41$ \\
\hline HPD5 & $160.21 \pm 0.7806$ & $4-5$ & $3.42 \pm 0.11$ & 0.29 & $99.63 \pm 0.55$ \\
\hline HPD6 & $170.40 \pm 0.8484$ & $4-5$ & $3.48 \pm 0.05$ & 0.35 & $100.37 \pm 0.48$ \\
\hline CD1 & $115.39 \pm 2.3391$ & $4-5$ & $3.08 \pm 0.07$ & 0.38 & $100.10 \pm 0.46$ \\
\hline CD2 & $126.37 \pm 1.0960$ & $4-5$ & $3.17 \pm 0.13$ & 0.41 & $99.89 \pm 1.45$ \\
\hline CD3 & $135.35 \pm 0.4815$ & $4-5$ & $3.26 \pm 0.06$ & 0.35 & $99.64 \pm 0.21$ \\
\hline CD4 & $145.16 \pm 0.8764$ & $4-5$ & $3.41 \pm 0.07$ & 0.27 & $99.51 \pm 0.84$ \\
\hline
\end{tabular}

preparation was found to be within the specified limits of the stated amount of diclofenac sodium, indicating that the test complies with the official compendia test for tablets as per Indian pharmacopoeia (IP). Thus, diclofenac sodium controlled release tablets prepared with the selected polymers were regarded as good quality, fulfilling the official requirements of tablets.

\section{In vitro dissolution studies}

The influence of $\mathrm{pH}$ on dissolution behavior of a pharmaceutical product plays a very important role. Biological fluids show indeed a high variability in $\mathrm{pH}$ values influencing either the amount of drug reaching circulatory system after oral administration or the place of absorption along the gastro intestinal tract. Diclofenac sodium solubility depends on the $\mathrm{pH}$ of the solution. Diclofenac sodium is more soluble in the alkaline media and it is slightly soluble in acid media. Therefore, in $\mathrm{pH}$ 1.2 percent diclofenac sodium released from the matrix tablets was less than $7 \%$ due to its low solubility in acidic media.

Formulations XGD1, XGD2, XGD3, XGD4, XGD5 and XGD6 with 2.2:10, 4.2:10, 6.2:10, 8.2:10, 10.2:10 and 12.2:10 ratio of xanthan gum-drug showed drug release $100.59,99.78,100.97,100.52,100.67$ and 100.40 \% within 12, 16, 20, 24, 28 and $32 \mathrm{~h}$ as shown in Fig. 1. In presence of water the hydrophilic polymers become hydrated, then swells to form a gel within and outside the matrix tablet. The gels will form a diffusion barrier within and around the tablet cores, increasing the diffusion path length of drug molecules which causes reduced drug release from the tablets. XGD4 formulation can be considered as an optimum formulation for oral controlled release of diclofenac sodium with xanthan gum. Formulations HPD1, HPD2, HPD3, HPD4, HPD5 and HPD6 with 1:10, 2:10, 3:10, 4:10, 5:10 and 6:10 ratio of hydroxy propyl methyl cellulose-drug showed drug release 99.56, 99.57, 100.06, 99.90, 100.16 and $99.77 \%$ with in $10,12,16,24,28$ and $32 \mathrm{~h}$ are showed in Fig. 2. There must be sufficient polymer content in a matrix system to form barrier. The barrier protects the drug from immediately releasing into the dissolution medium. If the polymer level is too low, a complete gel layer may not form. Polymer level increased in the formulation results in decreased drug release rate. HPD4 formulation can be considered as an optimum formulation for oral controlled release of diclofenac sodium with hydroxy propyl methyl cellulose.

Formulations CD1, CD2, CD3 and CD4 with 1:10, $2: 10,3: 10$ and 4:10 ratio of compritol-drug showed drug release $99.83,99.59,100.63$ and $99.82 \%$ with in 20, 24, 32 and 36 h respectively as shown in Fig. 3. Compritol is a waxy material owing hydrophobic property. At higher concentration, the rate and extent of drug release was significantly reduced due to increased tortuosity and reduced porosity of the matrix. CD2 formulation can be considered as an optimum formulation for oral controlled release of diclofenac sodium with compritol. 


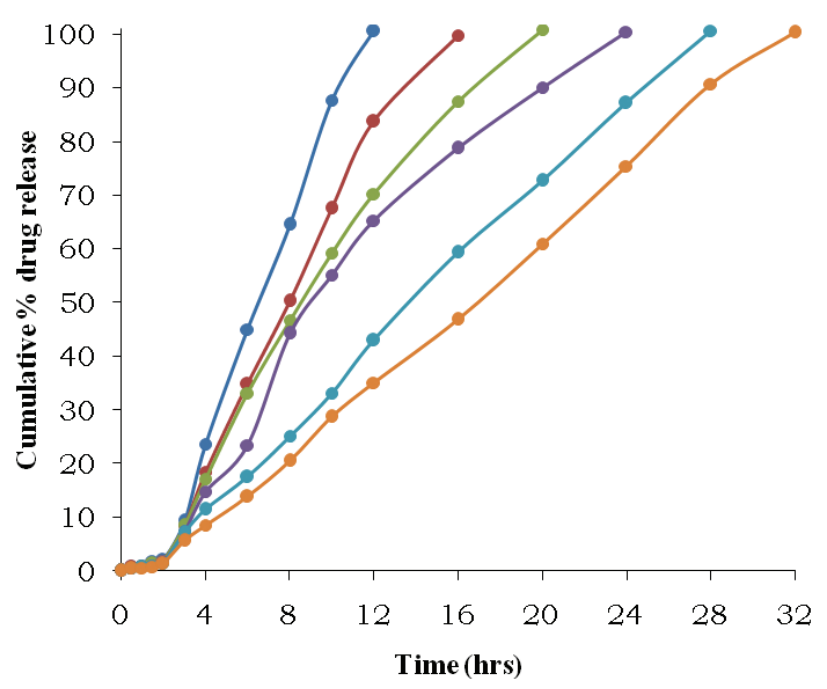

Figure 1: Dissolution profiles of xanthan gum matrix tablets of diclofenac sodium (XGD1 to XGD6)

$\rightarrow$ XGD1 $\rightarrow$ XGD2 $\rightarrow$ XGD3 $\rightarrow$ XGD4 $\rightarrow$ XGD5 $\rightarrow$ XGD6

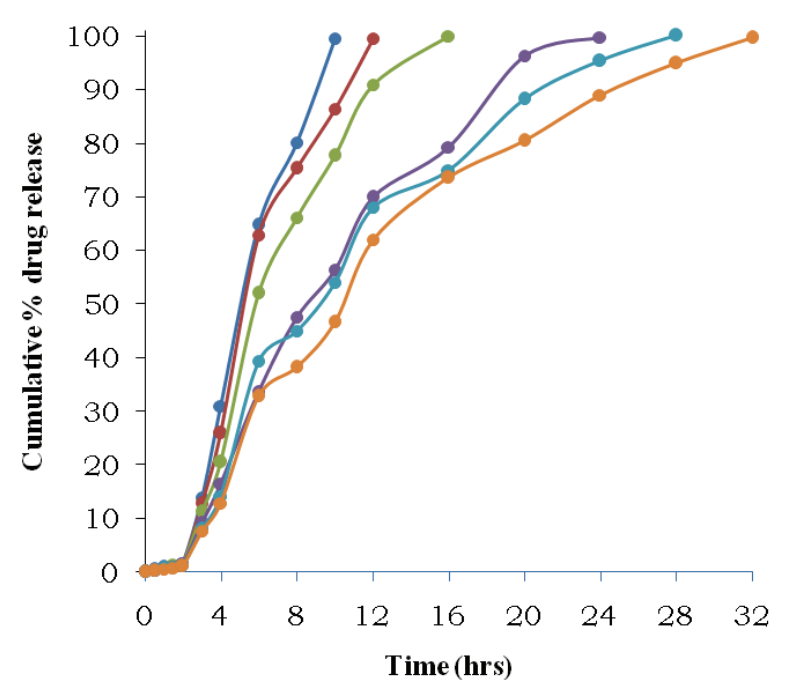

Figure 2: Dissolution profiles of hydroxy propyl methyl cellulose matrix tablets of diclofenac sodium (HPD1 to HPD6)

$\rightarrow$ HPD $1 \rightarrow$ HPD $2 \rightarrow-$ HPD3 $\rightarrow-\mathrm{HPD} 4 \rightarrow-\mathrm{HPD} 5 \rightarrow \mathrm{HPD} 6$

\section{Drug release kinetics}

The correlation coefficient ( $r$ ) values of zero order and first order kinetics of all formulations are shown in Table 5. The regression value of the formulations confirmed zero order release kinetics for XGD1 to XGD6, HPD1 to HPD6 and CD1 to CD4. Tablets prepared with xanthan gum, hydroxy propyl methyl cellulose and compritol matrix tablets showed zero order drug release.

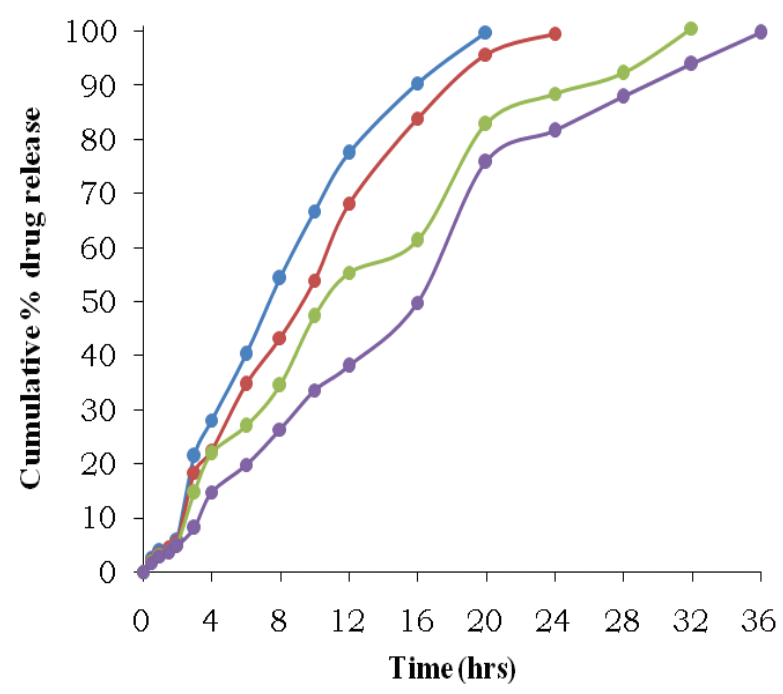

Figure 3: Dissolution profiles of compritol matrix tablets of diclofenac sodium (CD1 to CD4
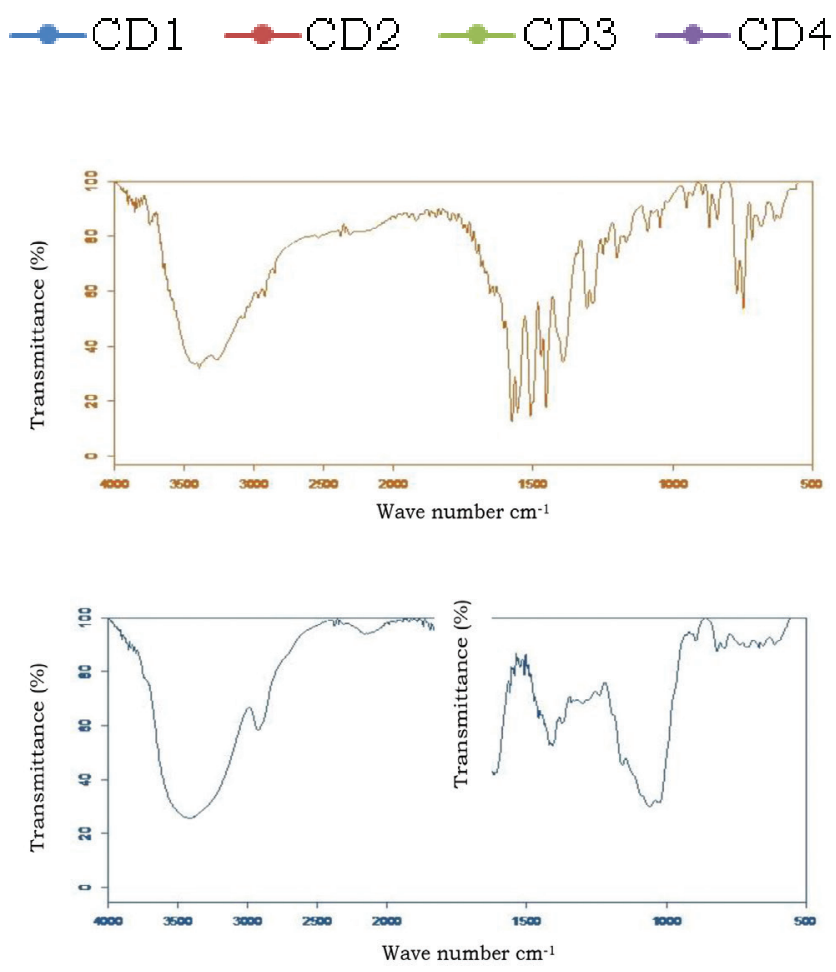

(b)

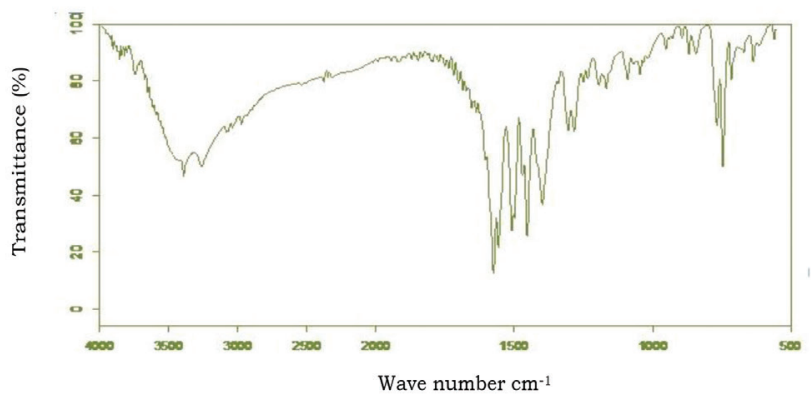

(c)

Figure 4: FTIR spectra of (a) diclofenac sodium (b) xanthan gum (c) formulation XGD4 
Table 5: Correlation coefficients ( $r$ ) values of drug release Kinetics of matrix tablets of diclofenac sodium

\begin{tabular}{|c|c|c|c|c|}
\hline \multirow{2}{*}{ Formulation } & \multicolumn{2}{|c|}{ Zero order } & \multicolumn{2}{c|}{ First order } \\
\cline { 2 - 5 } & $\begin{array}{c}\mathbf{k}_{\mathbf{0}} \\
\left(\mathbf{m g} \cdot \mathbf{h}^{-1}\right)\end{array}$ & $\mathbf{r}$ & $\begin{array}{c}\mathbf{k}_{\mathbf{1}} \\
\left.\mathbf{( h}^{-1}\right)\end{array}$ & $\mathbf{R}$ \\
\hline XGD1 & 7.719 & 0.9602 & 0.147 & 0.8922 \\
\hline XGD2 & 6.317 & 0.9834 & 0.111 & 0.9225 \\
\hline XGD3 & 5.355 & 0.9884 & 0.101 & 0.9497 \\
\hline XGD4 & 4.597 & 0.9844 & 0.094 & 0.9623 \\
\hline XGD5 & 3.559 & 0.9935 & 0.053 & 0.9618 \\
\hline XGD6 & 3.082 & 0.9955 & 0.044 & 0.9534 \\
\hline HPD1 & 9.456 & 0.9612 & 0.159 & 0.9022 \\
\hline HPD2 & 8.467 & 0.9694 & 0.166 & 0.9327 \\
\hline HPD3 & 7.094 & 0.9691 & 0.177 & 0.8899 \\
\hline HPD4 & 4.774 & 0.9783 & 0.118 & 0.9214 \\
\hline HPD5 & 4.549 & 0.9721 & 0.092 & 0.9685 \\
\hline HPD6 & 4.176 & 0.9783 & 0.076 & 0.9778 \\
\hline CD1 & 5.731 & 0.9788 & 0.122 & 0.9672 \\
\hline CD2 & 4.802 & 0.9818 & 0.118 & 0.9354 \\
\hline CD3 & 4.031 & 0.9884 & 0.071 & 0.9633 \\
\hline CD4 & 3.417 & 0.9945 & 0.051 & 0.9333 \\
\hline & & & & \\
\hline
\end{tabular}

Table 6: Correlation coefficients $(r)$ values of drug release mechanism of matrix tablets of diclofe nac sodium

\begin{tabular}{|c|c|c|}
\hline Formulation & $\begin{array}{c}\text { Higuchi } \\
\mathbf{r}\end{array}$ & $\begin{array}{c}\text { Erosion } \\
\mathbf{r}\end{array}$ \\
\hline XGD1 & 0.8055 & 0.9236 \\
\hline XGD2 & 0.8637 & 0.9466 \\
\hline XGD3 & 0.8944 & 0.9721 \\
\hline XGD4 & 0.9072 & 0.9803 \\
\hline XGD5 & 0.8862 & 0.9757 \\
\hline XGD6 & 0.8689 & 0.9798 \\
\hline HPD1 & 0.9618 & 0.9518 \\
\hline HPD2 & 0.9706 & 0.9696 \\
\hline HPD3 & 0.9757 & 0.9737 \\
\hline HPD4 & 0.9884 & 0.9869 \\
\hline HPD5 & 0.9864 & 0.9935 \\
\hline HPD6 & 0.9879 & 0.9943 \\
\hline CD1 & 0.9921 & 0.9829 \\
\hline CD2 & 0.9915 & 0.9889 \\
\hline CD3 & 0.9922 & 0.9899 \\
\hline CD4 & 0.9813 & 0.9757 \\
\hline
\end{tabular}

\section{Drug release mechanism}

The drug release mechanism was determined by fitting dissolution data to the linear regression plots for dissolution profiles. Higuchi and erosion plot were drawn and correlation coefficients of release mechanism of all formulations are shown in Table 6 .

\section{Drug-excipient compatibility studies}

The excipients chosen, their concentration and characteristics can influence the final drug product. According to international conference on harmonization ( $\mathrm{ICH}$ ) guidelines drug-excipient compatibility studies are normally carried for physical mixture of drug and selected excipient. ${ }^{35}$ However there is a possibility of drug-excipient incompatibility during compression due to heat and other factors (processing variables) rather than physical mixture. Hence compatibility studies were carried for matrix tablets instead of physical mixtures. For other polymers also compatibility studies for physical mixtures were not done because these polymers were earlier reported for their applicability for diclofenac sodium. Drug-polymer interactions were carried for the optimized formulations. The techniques employed in the present work to study the drug-polymer interactions are fourier
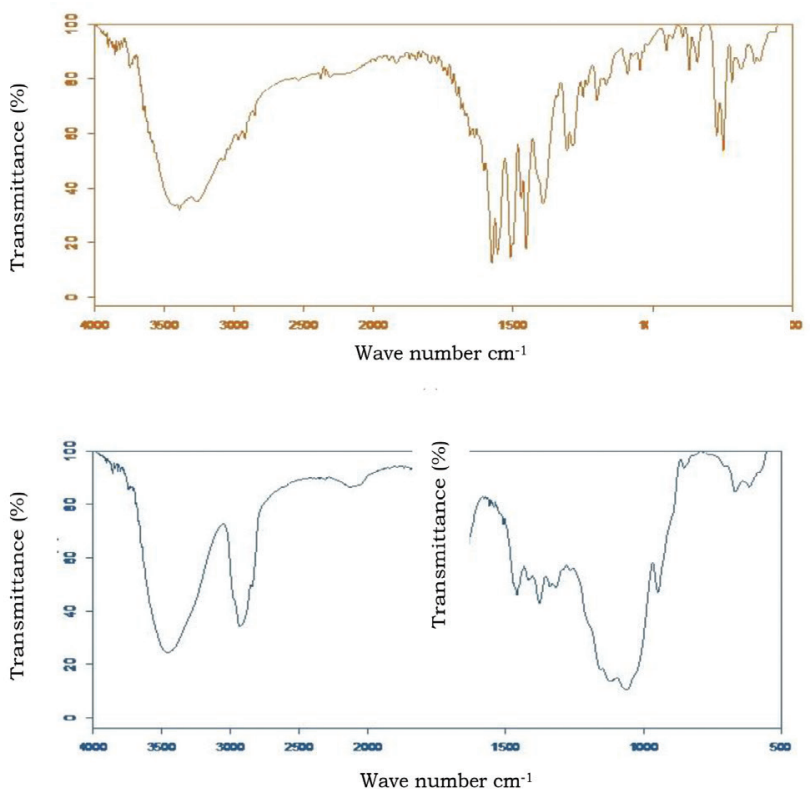

(b)

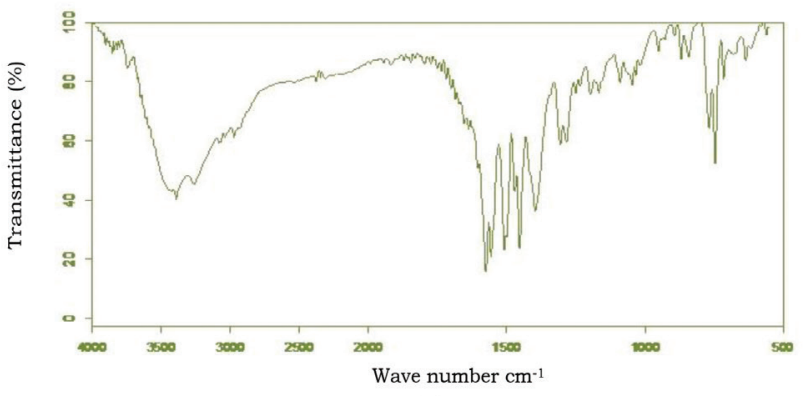

(c)

Figure 5: FTIR spectra of (a) diclofenac sodium (b) hydroxy propyl methyl cellulose (c) formulation HPD4 

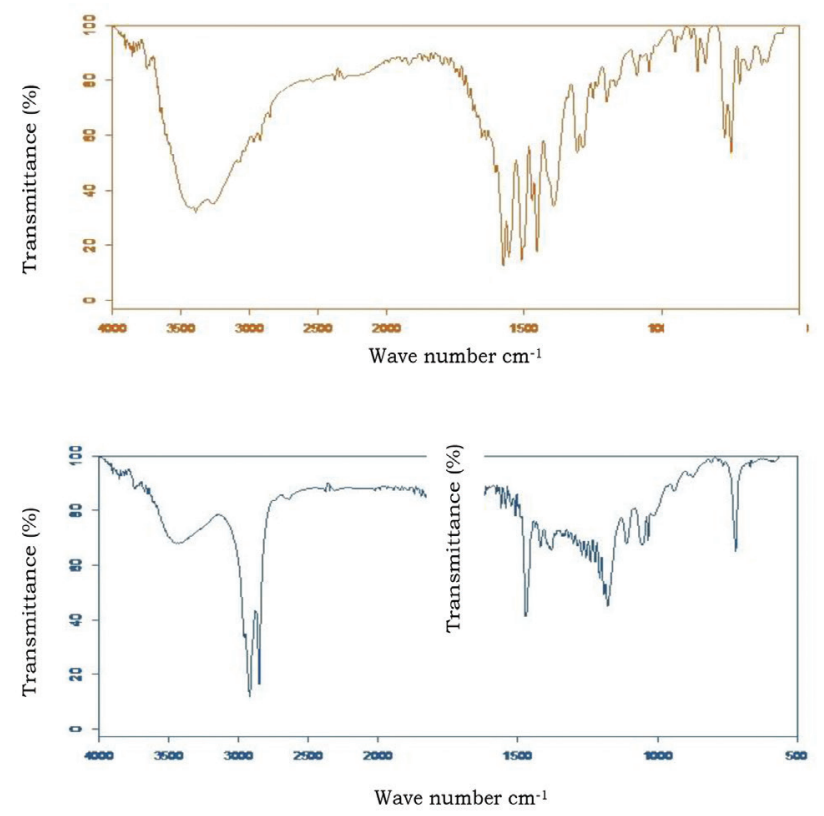

(b)

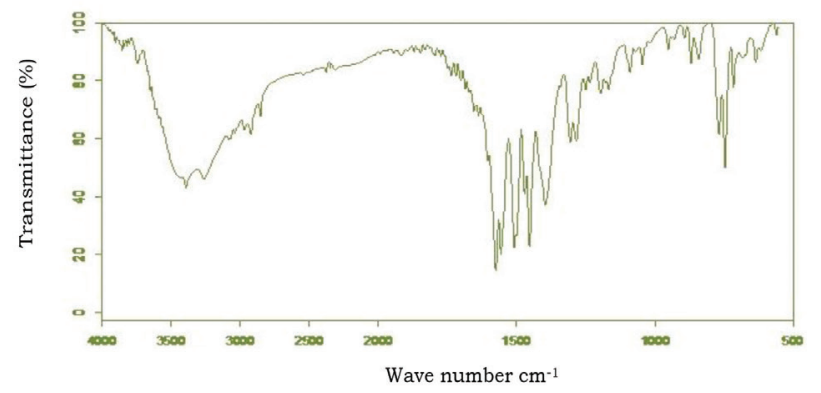

(c)

Figure 6: FTIR spectra of (a) diclofenac sodium (b) compritol (c) formulation CD2

transform infrared spectroscopy, differential scanning calorimetry and X-ray diffraction studies.

\section{Infrared spectroscopy (FTIR) studies}

The FTIR spectra of pure drug diclofenac sodium, pure polymers (AHG, xanthan gum, hydroxy propyl methyl cellulose and compritol) used in study and their respective selected formulations (XGD4, HPD4 and CD2) are shown in Fig. 4 to 6.The fourier transform infrared spectra of diclofenac sodium showed the principle absorption peaks at $3381.26 \mathrm{~cm}^{-1}$ due to $-\mathrm{NH}$ stretching of secondary amines, $1575.31 \mathrm{~cm}^{-1}$ due to $-\mathrm{C}=\mathrm{O}$ stretching of carboxyl ions and $770.36 \mathrm{~cm}^{-1}$ due to $\mathrm{C}-\mathrm{Cl}$ stretching in the spectrum. Pure xanthan gum showed characteristic alcoholic peak at $3421.15 \mathrm{~cm}^{-1}$, - $\mathrm{CH}$ stretch at 2930.64 $\mathrm{cm}^{-1},-\mathrm{C}=\mathrm{O}$ stretch at $1733.91 \mathrm{~cm}^{-1},-\mathrm{C}=\mathrm{CH}_{2}$ stretch at $1617.02 \mathrm{~cm}^{-1}$, -C-O-C- stretch at $1239.17 \mathrm{~cm}^{-1}$ and $1058.72 \mathrm{~cm}^{-1}$. XGD4 formulation showed characteristic
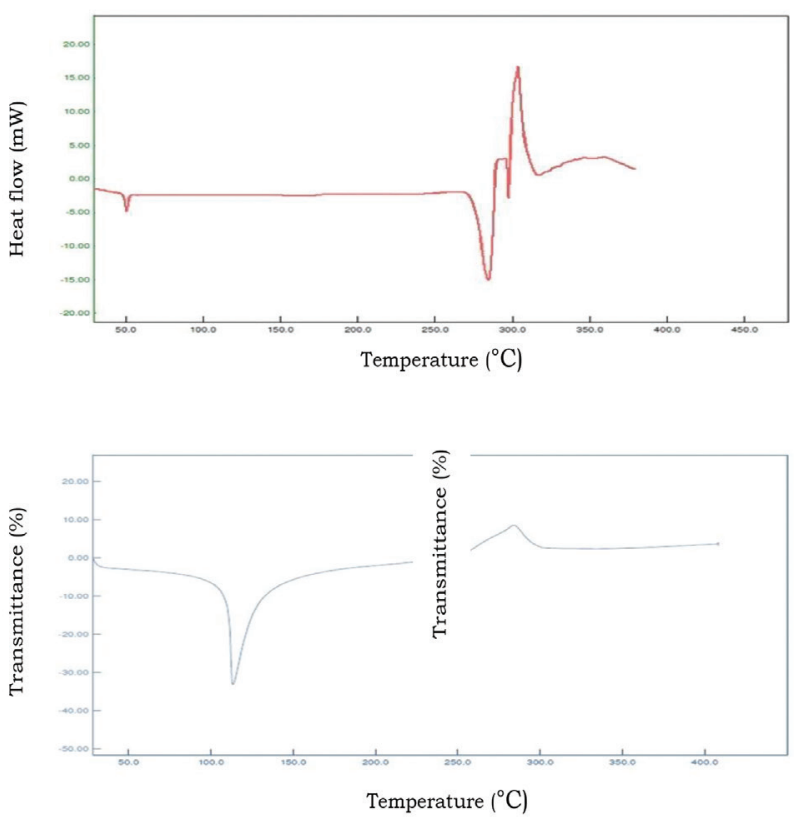

(b)

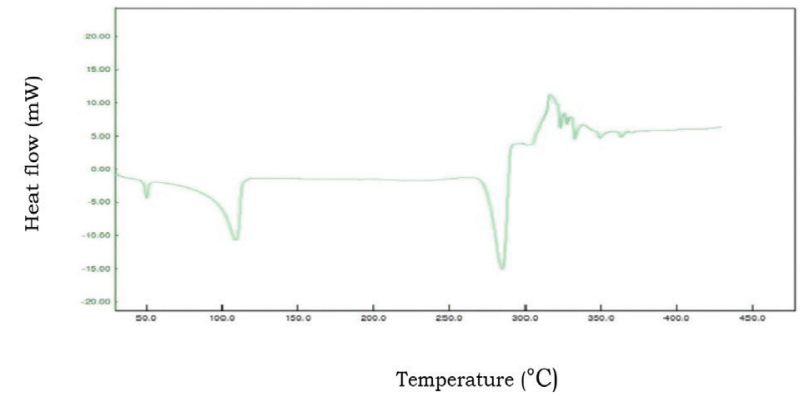

(c)

Figure 7: DSC spectra of (a) diclofenac sodium (b) xanthan gum (c) formulation XGD4

drug peaks at $3387.28 \mathrm{~cm}^{-1}, 1574.58 \mathrm{~cm}^{-1}$ and $766.74 \mathrm{~cm}^{-1}$ with minor shifts.

Hydroxy propyl methyl cellulose pure polymer showed an alcoholic stretch at $3456.43 \mathrm{~cm}^{-1},-\mathrm{C}=\mathrm{CH}_{2}$ stretch at $1653.70 \mathrm{~cm}^{-1}$, -C-O-C- asymmetric stretch at $1120.88 \mathrm{~cm}^{-1}$ and $-\mathrm{C}-\mathrm{O}-\mathrm{C}$ - symmetric stretch at $1060.45 \mathrm{~cm}^{-1}$. In diclofenac formulation HPD4 showed minor shift of drug peaks at $3387.57 \mathrm{~cm}^{-1}, 1574.84 \mathrm{~cm}^{-1}$ and 768.12 $\mathrm{cm}^{-1}$. Compritol pure polymer showed an alcoholic stretch at $3442.91 \mathrm{~cm}^{-1},-\mathrm{C}=\mathrm{O}$ stretch at $1735.61 \mathrm{~cm}^{-1}$, $-\mathrm{O}-\mathrm{C}=\mathrm{C}$ asymmetric stretch at $1178.11 \mathrm{~cm}^{-1}$ and $-\mathrm{C}-\mathrm{O}-$ C- stretch at $1054.76 \mathrm{~cm}^{-1}$. In diclofenac formulation CD2 showed minor shift of drug peaks at $3387.57 \mathrm{~cm}^{-1}$, $1574.78 \mathrm{~cm}^{-1}$ and $768.30 \mathrm{~cm}^{-1}$.

\section{Differential scanning calorimetry (DSC)}

The thermograms of pure drug diclofenac sodium, pure polymers (xanthan gum, hydroxy propyl methyl cellulose and compritol) and selected formulations 


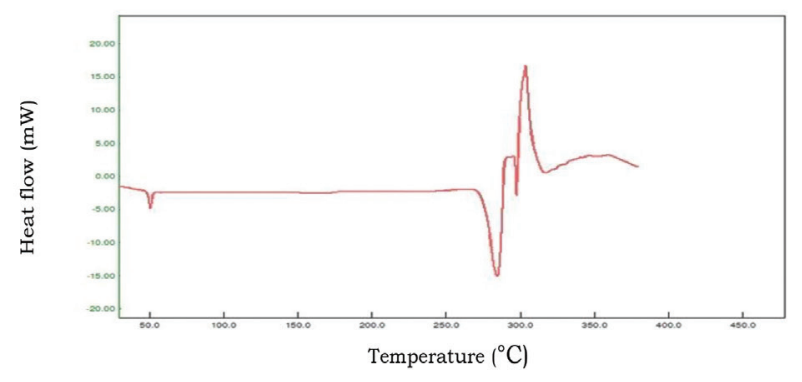

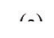

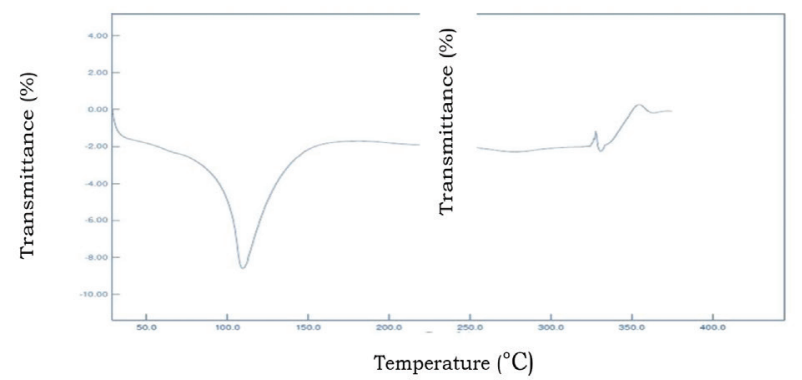

(b)

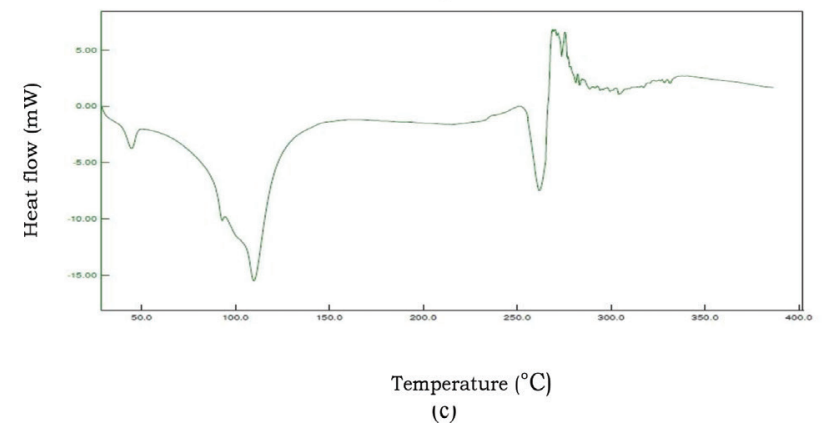

Figure 8: DSC spectra of (a) diclofenac sodium (b) hydroxy propyl methyl cellulose (c) formulation HPD4

(XGD4, HPD4 and CD2) are shown in Fig. 7 to 9.DSC thermogram of diclofenac sodium showed an endothermic peak at $283.5^{\circ} \mathrm{C}$, this was in correlation with the melting point of the drug. The endothermic peaks were observed at $114{ }^{\circ} \mathrm{C}, 108{ }^{\circ} \mathrm{C}$ and $71.8{ }^{\circ} \mathrm{C}$ for xanthan gum, hydroxy propyl methyl cellulose and compritol respectively. The formulations XGD4, HPD4 and $\mathrm{CD} 2$ showed endothermic peak of diclofenac sodium at $275.7^{\circ} \mathrm{C}, 260.6^{\circ} \mathrm{C}$ and $251.3^{\circ} \mathrm{C}$ respectively. The slight change of melting peak of diclofenac sodium in prepared formulations XGD4, HPD4 and CD2 may be due to addition of the polymers. The polymers selected in the study were with melting points less than diclofenac sodium and are hydrophilic in nature. The low melting point of the polymer might have influenced the melting point of pure drug of diclofenac sodium. This may be the reason for the change in endothermic peak of drug. Hence the slight variation in melting peaks of diclofenac sodium was due to physical interaction and not because

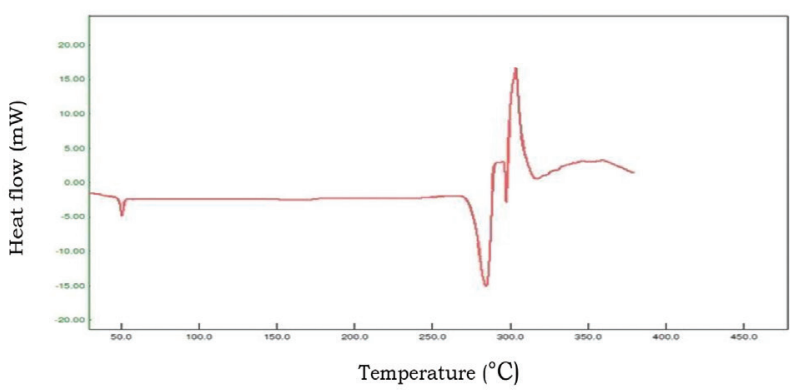

(n)

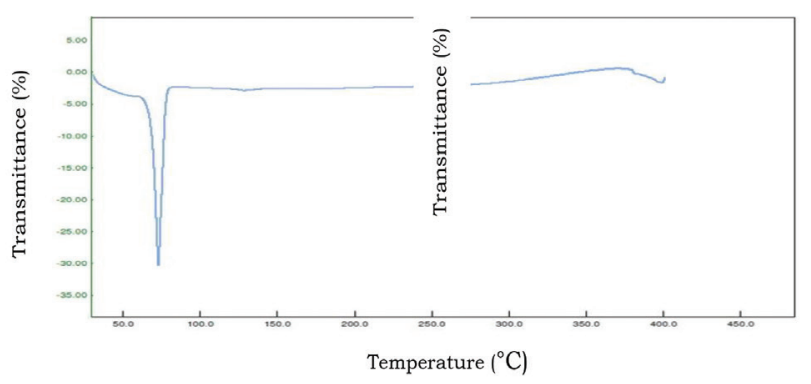

(b)

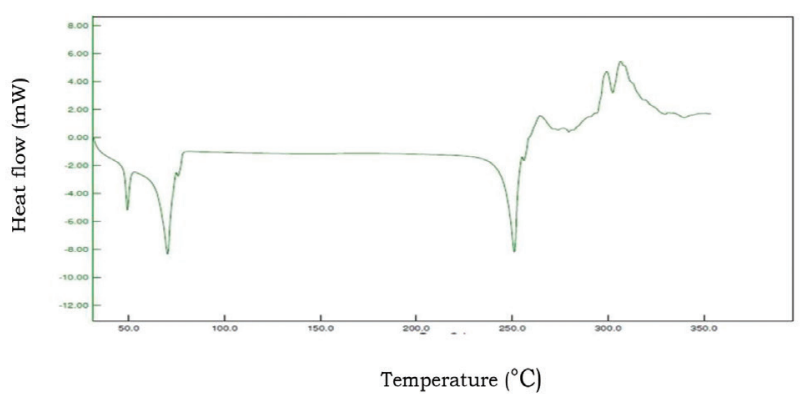

(c)

Figure 9: DSC spectra of (a) diclofenac sodium (b) compritol (c) formulation CD2

of either chemical interaction or complexation between diclofenac and AHG, xanthan gum, hydroxy propyl methyl cellulose and compritol during manufacturing process.

\section{X-ray diffraction studies}

The X-ray diffracto gram of pure drug diclofenac sodium, pure polymers (xanthan gum, hydroxy propyl methyl cellulose and compritol) used in study and selected formulations (XGD4, HPD4 and CD2) are shown in Fig.10 to 12 .The X-ray diffracto gram of diclofenac sodium showed sharp peaks at $15.3128^{\circ}, 17.3405^{\circ}$, $20.1200^{\circ}, 20.4000^{\circ}, 21.1600^{\circ}, 23.4000^{\circ}, 23.6000^{\circ}$, $27.1683^{\circ}$ and $27.9553^{\circ} 2 \theta$ indicating the crystallinity of the drug. Pure polymers xanthan gum and hydroxy propyl methyl cellulose showed broad peaks at $44.0599^{\circ}$, $64.4305^{\circ}, 77.5498^{\circ} 2 \theta$ (xanthan gum) and $19.3000^{\circ}$, $20.4800^{\circ}, 37.8190^{\circ}, 44.0561^{\circ}, 64.4204^{\circ}, 77.5425^{\circ} 2 \theta$ (hydroxy propyl methyl cellulose) respectively. This 

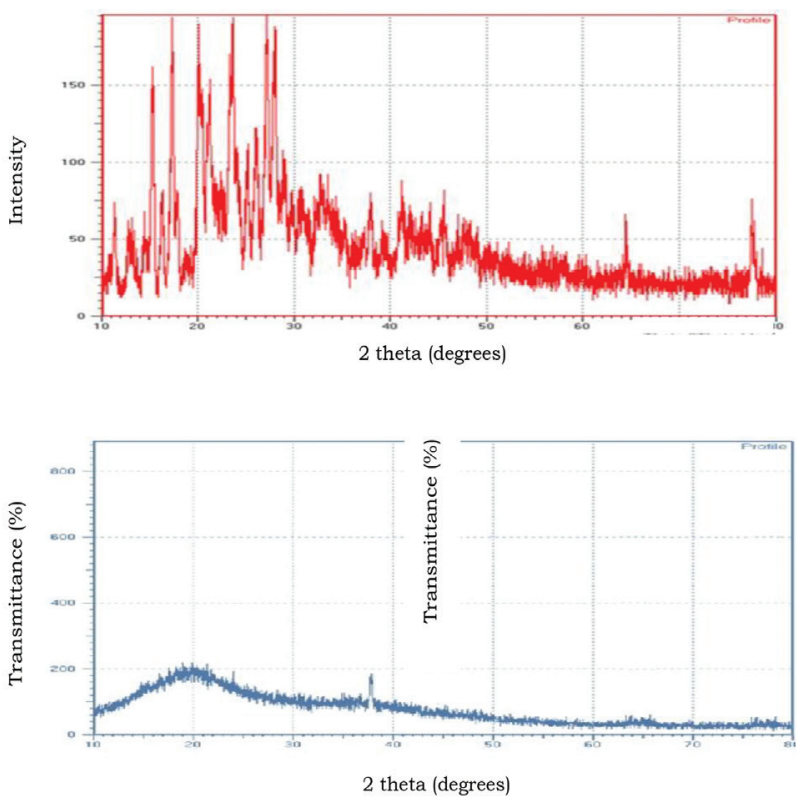

(b)

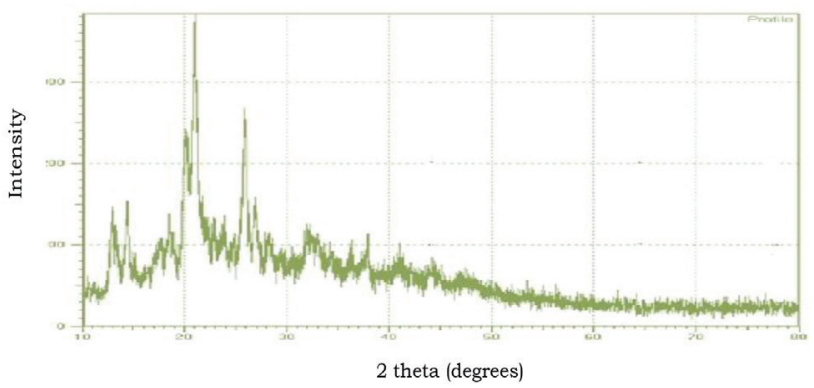

(c)

Figure 10: XRD patterns of (a) diclofenac sodium (b) xanthan gum (c) formulation XGD4

indicated that the polymers selected were amorphous in nature. Compritol showed sharp peaks at $21.0739^{\circ}$, $23.0731^{\circ}, 24.3400^{\circ}, 44.0630^{\circ}, 64.4271^{\circ}$ and $77.5531^{\circ}$ angle $2 \theta$ indicating the crystalline nature of the polymer. In formulation XGD4 the peaks observed at, along with characteristic peaks of pure polymer $12.9000^{\circ}, 14.3625^{\circ}$, $20.1400^{\circ}, 20.9766^{\circ}, 25.8690^{\circ}, 44.0781^{\circ}, 64.4377^{\circ}$ and $77.5582^{\circ} 2 \theta$. In HPD2 formulation peaks observed at $13.2633^{\circ}, 14.6500^{\circ}, 20.4200^{\circ}$ and $21.2857^{\circ} 2 \theta$. The intensity of some of the peaks was reduced and shifted slightly when compared to the pure drug. Formulation CD2 showed characteristic peaks of pure drug at, along with characteristic polymer peaks at $21.1500^{\circ}, 23.3966^{\circ}$, $26.9900^{\circ}, 27.7958^{\circ}, 44.0800^{\circ}$ and $77.5633^{\circ} 2 \theta$. Intensity of some peaks was reduced and some characteristic peaks of the pure drug were lost.

The changes in the X-ray diffraction patterns observed might be due to the fine dispersion of drug in the polymers during mixing and may be due to the compression force
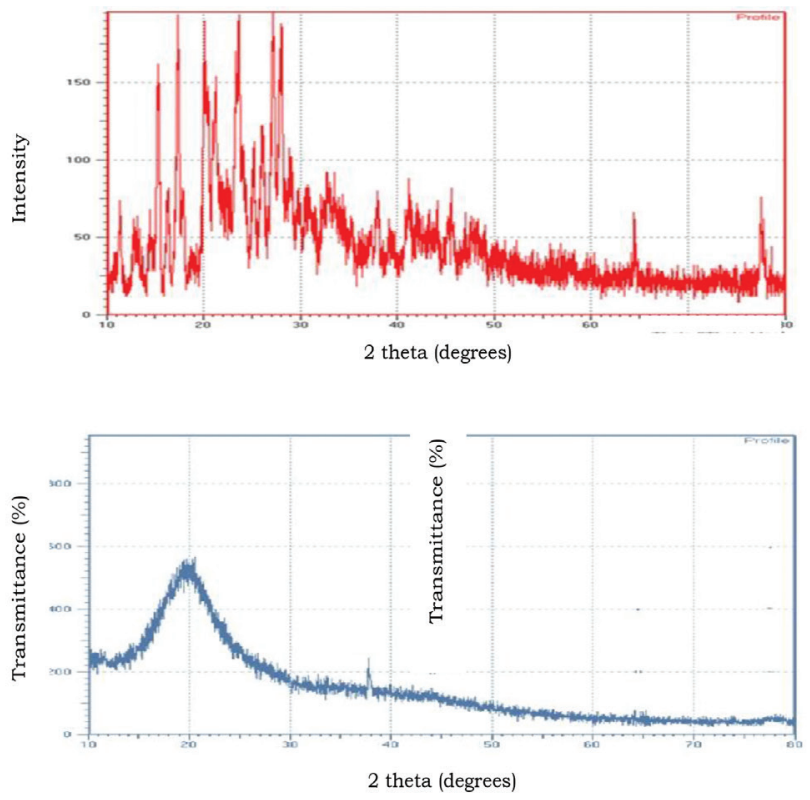

(b)

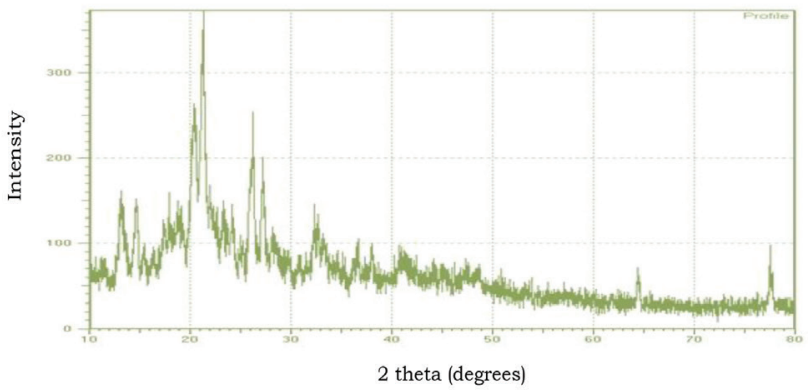

(c)

Figure 11: XRD patterns of (a) diclofenac sodium (b) hydroxy propyl methyl cellulose (c) formulation HPD4

applied during the preparation of the tablets. Therefore, it can be concluded as there is a physical interaction between the drug and polymers and not the chemical interaction.

\section{CONCLUSION}

All the formulations showed good tabletting characteristics. Polymers were selected for this study was natural (xanthan gum), semisynthetic (hydroxy propyl methyl cellulose) and synthetic (compritol). Matrix tablets were prepared with selected polymers and drug release profiles were carried. Drug release kinetics and drug release mechanism were evaluated. Fourier transform infrared spectroscopy (FTIR) analysis, differential scanning calorimetry (DSC) and X-Ray diffraction (XRD) studies indicated that there was no interaction between drug and polymers. 

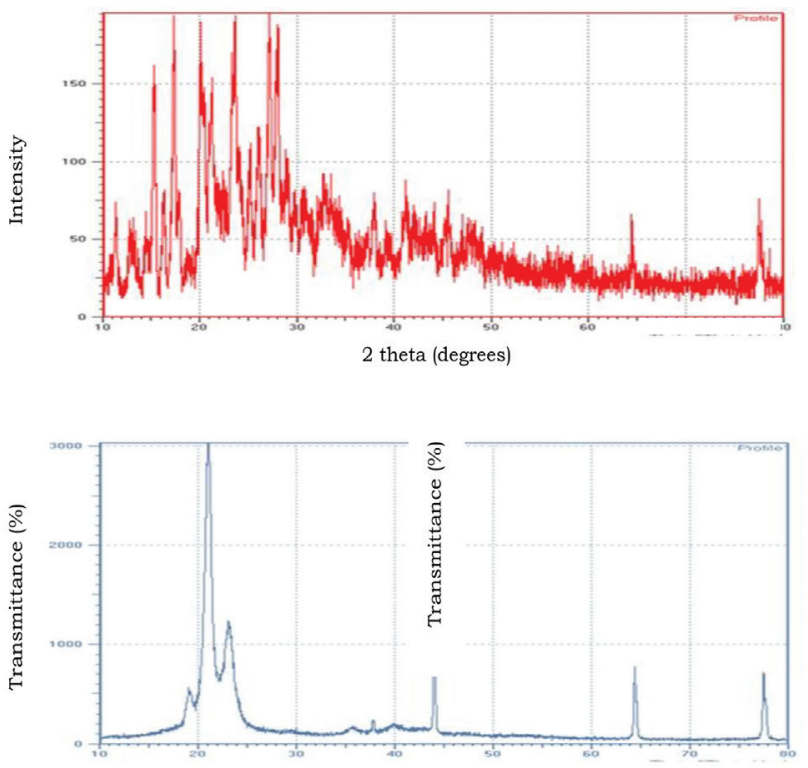

2 theta (degrees)

(b)

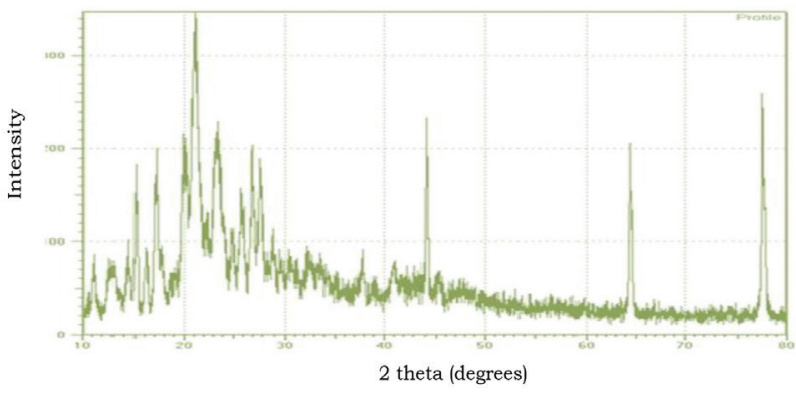

(c)

Figure 12: XRD patterns of (a) diclofenac sodium (b) compritol (c) formulation CD2

\section{ACKNOWLEDGEMENT}

We are thankful to K Sravya, S Rajeswari, Chaithanya Krishna $\mathrm{M}$ and Sudhakar B for providing valuable information to carry out this work.

\section{CONFLICT OF INTEREST}

The authors report no conflicts of interest. The authors alone are responsible for the content and writing of this article.

\section{ABBREVATIONS USED}

HPMC: Hydroxy propyl methyl cellulose; PVP: Poly vinyl pyrrolidone.

\section{REFERENCES}

1. Chen X. Challenges and new technologies of oral controlled release. In: Wen $\mathrm{H}$ and Park K Eds. Oral controlled release formulation design and drug delivery: Theory to Practice. 2010;257-77. https://doi.org/10.1002/9780470640487.ch6.
2. Gupta PK, Robinson JR. Oral controlled release delivery. In: Kyodenius A Ed. Treatise on controlled drug delivery. New York: Marcel Dekker; 1992;255-313. PMid:1344162.

3. Maderuelo C, Zarzuelo A, Lanao JM. Critical factors in the release of drugs from sustained release hydrophillic matrices. J Control Release. 2011;154:2-19. https://doi.org/10.1016/j.jconrel.2011.04.02 PMid:21497624.

4. Tongwen $\mathrm{X}$, Binglin $\mathrm{H}$. Mechanism of sustained drug release in diffusion controlled polymer matrix application of percolation theory. Int JPharma. 1998;170(2):139-49. https://doi.org/10.1016/S0378-5173(97)00402-X.

5. Nair AB, Vyas $\mathrm{H}$, Kumar A. Controlled release matrix uncoated tablets of enalapril maleate using HPMC alone. J Basic ClinPharma. 2010;1(2):71-75. PMid:24825968 PMCid:PMC3979173.

6. Rajput GC, Majmudar FD, Patel JK, Thakor RS, Patel BP, Rajgor NB. Stomach specific mucoadhesive microsphere as a controlled drug delivery system. Int J PharmaBiol Res. 2010;1:30-41. https://doi.org/10.4103/09758453.59515.

7. Grundy JS, Foster RT. The nifedipine gastrointestinal system: Evaluation of pharmaceutical, pharmacokinetic and pharmacological properties. Clinical Pharmacokinetics. 1996;30(1):28-51. https://doi.org/10.2165/00003088199630010-00003 PMid:8846626.

8. Lordi NG. Sustained release dosage form: In theory and practice of industrial pharmacy. 3rd ed. Philadelphia, USA: Lea and Febige. 1986;430-456.

9. Kourounakis AP, Galanakis D, Tsiakitzis K, Rekka EA, Kourounakis PN. Synthesis and pharmacological evaluation of novel derivatives of antiinflammatory drugs with increased antioxidant and anti-inflammatory activities. Drug Dev Res. 1999;47(1):9-16. https://doi.org/10.1002/ (SICI)1098-2299(199905)47:1<9::AID-DDR2>3.0.CO;2-9.

10. Bumphrey G. Extremely useful, new suspending agent. Pharm J. 1986;237:66571.

11. Sharma BR, Naresh L, Dhuldhoya NC, Merchant SU, Merchant UC. Xanthan Gum-A Boon to food Industry. Food Promot Chron. 2006;1:27-30.

12. Kazbauer B. Properties and applications of xanthan gum. PolymDegradStabil. 1998;59:81-4. https://doi.org/10.1016/s0141-3910(97)00180-8.

13. Talukdar M, Van den MG, Augustijins P, Tjandra MT, Verbeke N, Kinget R. In vivo evaluation of xanthan gum as a potential excipient for oral controlledrelease matrix tablet formulation. Int J Pharm. 1998;169(1):105-13. https:// doi.org/10.1016/S0378-5173(98)00112-4.

14. Bumphrey G. Extremely useful, new suspending agent. Pharm J. 1986;237:665-71.

15. Sharma BR, Naresh L, Dhuldhoya NC, Merchant SU, Merchant UC. Xanthan Gum-A Boon to food Industry. Food Promot Chron. 2006;1:27-30.

16. Kazbauer B. Properties and applications of xanthan gum. PolymDegradStabil. 1998;59:81-4. https://doi.org/10.1016/s0141-3910(97)00180-8.

17. Lu MF, Woodward L, Borodkin S. Xanthan gum and alginate based controlled release theophyllin formulations. Drug Devlnd Pharm. 1991;17(14):1987-2004 https://doi.org/10.3109/03639049109048063.

18. Dhopeshwarkar V, Zatz JL. Evaluation of xanthan gum in the preparation of sustained release matrix tablets. Drug Devlnd Pharm. 1993;19(9):999-1017. https://doi.org/10.3109/03639049309062997.

19. Chowhan ZT. Role of binders in moisture-induced hardness increase in compressed tablets and its effect on in vitro disintegration and dissolution. J Pharm Sci. 1980;69(1):1-4. https://doi.org/10.1002/jps.2600690102 PMid:7354417.

20. Rowe RC. The molecular weight and molecular weight distribution of hydroxypropyl methylcellulose used in the film coating of tablets. J Pharm Pharmacol. 1980;32(2):116-9. https://doi.org/10.1111/j.2042-7158.1980. tb12865.x PMid:6103031.

21. Banker G, Peck G, Steve Ja, Pirakitikular P, Taylor D. Evaluation of hydroxypropyl cellulose and hydroxypropyl methyl cellulose as aqueous based film coatings. Drug Devlnd Pharm. 1981;7(6):693-716. https://doi. org/10.3109/03639048109055693.

22. Hardy JG, Kennerley JW, Taylor MJ, Wilson CG, Davis SS. Release rates from sustained-release buccal tablets in man. J Pharm Pharmacol. 1982;34(12):91. https://doi.org/10.1111/j.2042-7158.1982.tb00922.x.

23. Hogan JE. Hydroxypropyl methylcellulose sustained release technology. Drug Devlnd Pharm. 1989;15(6-7):975-99. https://doi. org/10.3109/03639048909043660.

24. Dahl TC, Calderwood T, Bormeth A, Trimble K. Influence of physico-chemical properties of hydroxypropyl methylcellulose on naproxen release from sustained release matrix tablets. J Control Release. 1990;14(1):1-10. https:// doi.org/10.1016/0168-3659(90)90055-X. 
25. United state Pharmacopoeia 29-National Formulary 24. Rockville, USA: United state Pharmacopoeial Convention. 2006;3340-1.

26. Hariharan M, Wowchuk C, Nkansah P, Gupta VK. Effect of formulation composition on the properties of controlled release tablets prepared by roller compaction. Drug Devind Pharm. 2004;30(6):565-72. https://doi. org/10.1081/DDC-120037487 PMid:15285329.

27. Obaidat AA, Obaidat RM. Controlled release of tramadol hydrochloride from matrices prepared using glycerylbehenate. Eur J Pharm Biopharm. 2001;52(2):231-5. https://doi.org/10.1016/S0939-6411(01)00173-4.

28. Jannin V, Bérard V, N'Diaye A, Andrès C and Pourcelot Y. Comparative study of the lubricant performance of Compritol 888 ATO either used by blending or by hot melt coating. Int J Pharm. 2003;267(1-2):39-45. https:// doi.org/10.1016/S0378-5173(03)00316-8.

29. Barthelemy P, Laforêt JP, Farah N and Joachim J. Compritol 888 ATO: an innovative hot-melt coating agent for prolonged release drug formulations. Eur J Pharm Biopharm. 199;47(1):87-90.

30. Faham A, Prinderre P, Farah N, Eichler KD, Kalantzis $G$ and Joachim J. Hotmelt coating technology. I. Influence of Compritol 888 ATO and granule size on theophylline release. Drug Devlnd Pharm. 2000;26(2):167-76. https://doi. org/10.1081/DDC-100100341 PMid:10697753.

31. Faham A, Prinderre P, Piccerelle P, Farah N and Joachim J. Hot melt coating technology: influence of compritol 888 ATO and granule size on chloroquine release. Pharmazie. 2000;55(6):444-8. PMid:10907253.

32. Freitas $\mathrm{C}$, Muller $\mathrm{RH}$. Correlation between long-term stability of solid lipid nanoparticles (SLN) and crystallinity of the lipid phase. Eur J Pharm Biopharm. 1999;47(2):125-32. https://doi.org/10.1016/S0939-6411(98)00074-5.

33. Maggi L, Segale L, Torre ML, Mashiste EO and Conte U. Dissolution behaviour of hydrophilic matrix tablets containing two different polyethylene oxides (PEOs) for controlled release of a water-soluble drug. Dimensional study. Biomaterials. 2002;23(4):1113-9. https://doi.org/10.1016/S01429612(01)00223-X

\section{Pictorial Abstract}

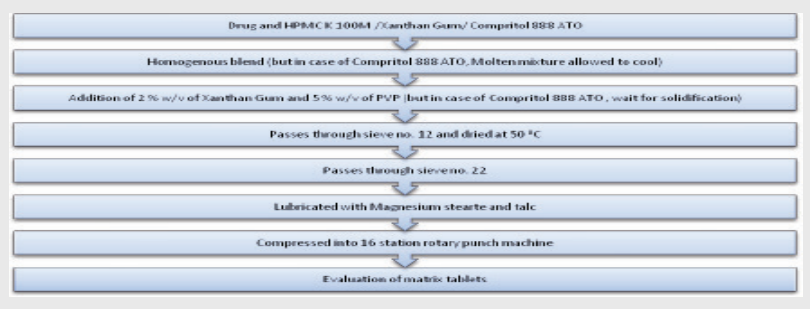

\section{About Authors}
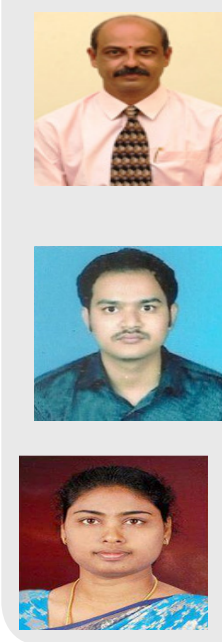
workshops. in conferences/ seminars.
34. Indian Pharmacopoeia, Vol. II. Govt. of India, Ministry of Health and Family Welfare. New Delhi: Controller of Publication. 2007;182.

35. Banker GS and Anderson NR. In: Lachman L, Lieberman HA and Kanig, JL Eds. The theory and practice of Industrial Pharmacy, 3rdEdn, 4th reprint, Bombay: Verghese Publishing House; 1991, 297.

36. Indian Pharmacopoeia, Vol. II. Govt. of India, Ministry of Health and Family Welfare. New Delhi: Controller of Publication. 2007;183.

37. Indian Pharmacopoeia, Vol. II. Govt. of India, Ministry of Health and Family Welfare. New Delhi: Controller of Publication. 2007;404.

38. Indian Pharmacopoeia, Vol. I. Govt. of India, Ministry of Health and Family Welfare. New Delhi: Controller of Publication. 1996;244.

39. United States Pharmacopoeia 24-national Formulary 19. Twinbrrok Parkway, Rockville, USA: United States Pharmacopoeial convention. 1995;546-542.

40. Lazarus J, Cooper J. Absorption, testing and clinical evaluation of oral prolonged-action drugs. J Pharm Sci. 1961;50(9):715-32. https://doi. org/10.1002/jps.2600500902 PMid:13759773.

41. Wagner JG. Interpretation of percent dissolved-time plots derived from in vitro testing of conventional tablets and capsules. J Pharm Sci. 1969;58(10):1253-7. https://doi.org/10.1002/jps.2600581021.

42. Higuchi T. Mechanism of sustained action medication: theoretical analysis of rate release of solid drugs dispersed in solid matrices. J Pharm Sci. 1963;52(12):1145-9. https://doi.org/10.1002/jps.2600521210.

43. Hixson AW, Crowell JH. Dependence of reaction velocity upon surface and agitation: I-theoretical consideration. IndEng Chem. 1931;23(10):923-31. https://doi.org/10.1021/ie50260a018.

44. ICH Harmonized Tripartite Guideline on: Stability Testing of New Drug Substances and Products ICH Q1A(R2). Europe, Japan and USA: ICH Expert Working Group; 6 February 2003.

\section{SUMMARY}

- Diclofenac sodium matrix tablets were prepared by using xanthan gum, HPMC K $100 \mathrm{M}$ and compritol for controlled release.

- $2 \% \mathrm{w} / \mathrm{v}$ of xanthan gum, $5 \% \mathrm{w} / \mathrm{v}$ of PVP was used as granulating agent. The polymers from natural origin (xanthan gum), semi synthetic origin (HPMC) and synthetic origin (compritol 888 ATO) were used as drug release retardants for controlled release matrix dosage forms.

Dr. K. V. Ramana Murthy: The professor of A.U. College of Pharmaceutical Sciences, Andhra University. He has four patents to his credit and has also authored several publications which include one book related to Pharmaceutical Technology sector. He is guiding several M.Pharm and $\mathrm{Ph} \mathrm{D}$ candidates for research projects sponsored by various government agencies. He has delivered several invited lecturers. He is a proactive associate in diverse capacities, of many professional Bodies viz. APTI,IPA etc. He is a recipient of several awards.

Sh.Lohithasu Duppala: Research Scholar of A.U. College of Pharmaceutical Sciences, Visakhapatnam has attained his M.Pharm from GITAM Institute of Pharmacy, Visakhapatnam in 2013. With teaching experience of one academic year, he has to his title more than fourty five publications in various national and international journals. He is a member of professional Bodies viz. IPGA,IPA etc. He has participated/ presented more than 25 national and international cconferences/seminars/

Dr. Hema Naga Durga: Has attained her Ph D from Andhra University, Visakhapatnam. She is published several papers in national and international journals and also presented several papers

Cite this article: Durga DHN, Lohithasu D, Murthy KVR. Development and Evaluation of Diclofenac sodium Controlled Release Dosage Forms Using Natural, Hydrophilic and Hydrophobic Polymers and its Comparative Studies. Indian $\mathrm{J}$ of Pharmaceutical Education and Research. 2017;51(1):116-27. 